\title{
Efficacy, safety and tolerability of tofacitinib in patients with an inadequate response to disease modifying anti-rheumatic drugs: a meta-analysis of randomized double-blind controlled studies
}

\author{
Asres Berhan
}

\begin{abstract}
Background: This meta-analysis was conducted to determine the efficacy, safety and tolerability of tofacitinib in the treatment of rheumatoid arthritis in patients with an inadequate response or intolerance to at least one of the nonbiologic or biologic disease-modifying antirheumatic drugs (DMARDs).

Methods: Electronic based literature search was conducted in the databases of HINARI (Health InterNetwork Access to Research Initiative), MEDLINE and Cochrane library. The studies included in the meta-analysis were double-blind randomized clinical trials that were conducted in treatment-refractory or intolerant patients with rheumatoid arthritis. The odds ratios (OR), standardized mean differences (SMD) and the $95 \%$ confidence intervals (95\% Cl) were determined by using the random effects model. Heterogeneity among the included studies was evaluated by $\mathrm{I}^{2}$ statistics.

Results: The odds of tofacitinib treated patients who met the criteria for an at least a $20 \%$ improvement in the American College of Rheumatology scale (ACR 20) was more than 4 times higher than placebo treated patients (overall $\mathrm{OR}=4.15 ; 95 \% \mathrm{Cl}, 3.23$ to 5.32 ). Even though the discontinuation rate due to adverse events was not different from placebo groups, tofacitinib was associated with infections (overall $\mathrm{SMD}=1.96,95 \% \mathrm{Cl}=1.428$ to 2.676), reduction in neutrophil counts (overall $S M D=-0.34,95 \% \mathrm{Cl}=-0.450$ to -0.223 ) and elevated levels of $L D L$ cholesterol and liver enzymes.

Conclusions: Tofacitinib was effective in the treatment of active rheumatoid arthritis in patients with an inadequate response or intolerance to at least one DMARDs. However, treatment with tofacitinib was associated with infections and laboratory abnormalities.
\end{abstract}

Keywords: ACR20 response, JAK Inhibitor, Meta-analysis, Rheumatoid arthritis, Tofacitinib

\section{Background}

Rheumatoid arthritis is a progressive autoimmune disease that results in a systemic chronic inflammation and destruction of the joints. Accordingly, the primary aim of rheumatoid arthritis treatment is to reduce the progression of the disease and to maximize long-term healthrelated quality of life [1]. The prevailing rheumatoid arthritis treatment approach comprises both non biologic (conventional) and biologic DMARDs [2].

Correspondence: asresb@hu.edu.et

Hawassa University College of Medicine and Health Sciences, P. O. Box: 1560, Hawassa, Ethiopia
The nonbiologic DMARDs are orally active small molecules; while biologic DMARDs are large proteins which are available as parenteral formulations. Of the non biologic DMARDs methotrexate is the most widely used $[3,4]$. Patients with an inadequate response to methotrexate are usually treated with biologic DMARDs such as tumor necrosis factor (TNF) inhibitors, either as monotherapy or in combination with nonbiologics DMARDs [2]. However, about $20-30 \%$ of the patients who were treated with biologic DMARDs monotherapy or in combination with nonbiologic DMARDs may not meet the ACR 20 improvement criteria (ACR20) [5-7]. On the 
other hand, some other patients discontinue medication due to adverse events.

Tofacitinib is a novel oral Janus kinase (JAK) inhibitor that is under investigation as a targeted immunomodulator and disease-modifying therapy in rheumatoid arthritis. In vitro and in vivo studies have demonstrated its efficacy in inhibiting osteoclast-mediated structural damage to arthritic joints [8,9]. Randomized double-blind controlled dose- ranging (1, 3, 5, 15, 20 and 30-mg) clinical trials have assessed the efficacy and safety of tofacitinib twice daily (BID) in treatment-refractory patients with rheumatoid arthritis. Most of the clinical trials on tofacitinib have reported the significant reductions in signs and symptoms of rheumatoid arthritis and improvement in physical function with manageable safety [10-13].

Though tofacitinib is approved recently by the food and drug administration (FDA) of America for the treatment of rheumatoid arthritis, no published meta-analysis has yet evaluated its consistent efficacy, safety and tolerability across studies. Thus the primary aim of this meta-analysis was to determine the efficacy, safety and tolerability of tofacitinib in the treatment of rheumatoid arthritis in patients with inadequate response or intolerance to at least one of the nonbiologic or biologic DMARDs.

\section{Methods}

\section{Search strategy}

Electronic based literature search was conducted in the databases of HINARI, MEDLINE and Cochrane library. Via HINARI, literature search was also conducted on the websites of major publishers (Elsevier Science-Science Direct, Wiley-Blackwell, Nature Publishing Group, Oxford University Press, PsycARTICLES, and Science). Furthermore, the literature search was strengthened by searching relevant articles from the reference lists of retrieved articles. During searching the following search terms were used alone or in an alternate combination with the help of Boolean operators (AND, OR, and NOT): tofacitinib, CP-690,550, JAK Inhibitor, rheumatoid arthritis, and ACR20 response.

\section{Inclusion criteria and study selection}

The predetermined study inclusion criteria for this metaanalysis were: 1 ) double- blind randomized clinical trial that assessed the efficacy and safety of tofacitinib as monotherapy or in combination with methotrexate in patients with rheumatoid arthritis who were on at least one of the nonbiologic or biologic DMARDs; 2) studies that recruited patients with rheumatoid arthritis that had been diagnosed for $\geq 6$ months and had active disease on the basis of the American College of Rheumatology 1987 revised criteria [14]. 3) Studies that were published in English.
The study selection was conducted in two stages. First, by reviewing the abstracts of all the retrieved literature, they were categorized as "eligible for full document review" and "ineligible for full document review". Secondly, the whole document of all the articles categorized as "eligible for full document review" were reviewed and categorized as "eligible for meta-analysis" and "ineligible for meta-analysis".

\section{Data extraction}

After developing a data extraction template, data extraction was conducted with standard Excel spreadsheets. From the included studies the following information were extracted: name of the first author, year of publication, study design, phase of the trial, duration of therapy, dose, sample size, name of drug(s) used as background regimen, ACR20 response rates, least squares means \pm standard errors (SE) or standard deviations (SD) for changes in laboratory test results and ACR 20 core component scores, number of patients who experienced adverse events, number of patients who discontinued medication due to adverse events, number of patients with alanine aminotransferase levels that were greater than one times the upper limit of the normal range (ALT >1 X ULN), number of patients with aspartate aminotransferase levels that were greater than one times the upper limit of the normal range (AST >1 X ULN) and incidences of infections.

\section{Operational definitions}

In the included studies ACR 20 was defined as at least a $20 \%$ reduction from baseline in the number of both tender and swollen joints and at least a $20 \%$ improvement in three or more of the five remaining ACR core set measures (patient's assessment of pain, level of disability, C-reactive protein level, global assessment of disease by the patient, and global assessment of disease by the physician [14]. Whereas, active disease was defined as the presence of 6 or more tender or painful joints (68 joint count) and 6 or more swollen joints (66 joint count) and either an erythrocyte sedimentation rate (ESR) above ULN or a C-reactive protein (CRP) level $>7$-mg/liter [14].

\section{Data synthesis \& statistical analysis}

For continues variables where SEs were reported instead of SDs, values for SDs were computed by multiplying the SEs with the square root of sample size $(\mathrm{SD}=\mathrm{SE} * \sqrt{N}$, where $\mathrm{N}=$ sample size). Similarly, when the value of serum creatinine was reported as $\mu \mathrm{mol} / \mathrm{L}$, it was converted to $\mathrm{mg} / \mathrm{dl}$ by dividing the values to 88.4 . The efficacy, safety and tolerability of tofacitinib 3, 5, 10, and 15-mg BID alone (monotherapy) or in combination with background methotrexate relative to placebo or placebo with background methotrexate in the treatment of rheumatoid 
arthritis were determined by using the random effects model. The OR and the 95\% CI for the number of patients with: at least a $20 \%$ improvement in ACR 20, ALT > 1 X ULN, AST > 1 X ULN, adverse events, infections and discontinued treatment due to adverse events were computed with Mantel-Haenszel method. The SMD and 95\% CIs for the mean changes in: laboratory test results (hemoglobin, neutrophils, serum creatinine, HDL cholesterol, and LDL cholesterol) and Health Assessment Questionnaire-Disability Index (HAQ DI) were computed using the inverse variance method. However, since tofacitinib 1-mg BID did not demonstrate a significant improvement in ACR20 in any of the included studies, tofacitinib 1-mg BID was excluded from the meta-analyses.

Heterogeneity among the included studies was assessed by the chi-squared test (Cochran $\mathrm{Q}$ test) and $\mathrm{I}^{2}$ statistics. When the value of $\mathrm{I}^{2}$ was greater than or equal to $50 \%$, it was considered as statistically significant. To assess the possible sources of heterogeneity among the included studies, subgroup analysis based on tofacitinib doses and type of therapy (monotherapy vs combination therapy) and meta-regression with two covariates (dose and duration of therapy) were conducted. Sensitivity analysis was also conducted to determine the robustness of the overall values and the change in $\mathrm{I}^{2}$ statistics when any of the included study was withdrawn (excluded) from the analysis. Risk of bias of individual studies was evaluated with the Cochrane risk of bias tool. On the other hand, publication or disclosure bias was assessed with funnel plots. However, tests for funnel plot asymmetry were not conducted as recommended in a metaanalysis that included less than ten studies [15]. All the statistical analyses were conducted by the OpenMetaAnalyst software.

\section{Results}

\section{Search result}

Based on the predetermined inclusion criteria, from the retrieved 43 publication, only eight double-blind randomized clinical trials [10-13,16-19] were included in the meta-analysis (Figure 1). Except one study [19] that was conducted in Japan at multiple sites all the included studies recruited patients with rheumatoid arthritis from more than one country. As shown in Table 1, five of the included studies compared the efficacy, safety and tolerability of tofacitinib in combination with background methotrexate against placebo with background methotrexate regimen $[10,12,13,18,19]$. While the remaining three studies compared tofacitinib monotherapy against placebo $[11,16,17]$. In all the included studies concomitant medication with stable doses of low-dose corticosteroids ( $\leq 10 \mathrm{mg}$ per day prednisone or equivalent), nonsteroidal anti-inflammatory drugs and selective cyclooxygenase- 2 inhibitors were allowed for all treatment groups (tofacitinib or placebo groups). From all the selected studies a total of 2,513 patients with rheumatoid arthritis have received one of the four doses of tofacitinib BID with or without methotrexate (3, 5, 10 or 15 -mg). While 1,770 patients (controls) have received placebo or placebo with background methotrexate. On the other hand, the risk of bias assessment among the included studies did not demonstrate the presences of biases in randomization, blinding and selective reporting.

\section{Efficacy}

As presented in Figure 2, the odds of tofacitinib treated patients who met the criteria for an ACR 20 response was more than 4 times higher than placebo treated patients (overall OR $=4.15$; 95\% CI, 3.23 to 5.32 ). Moreover, to the exception of one study [16], in all the

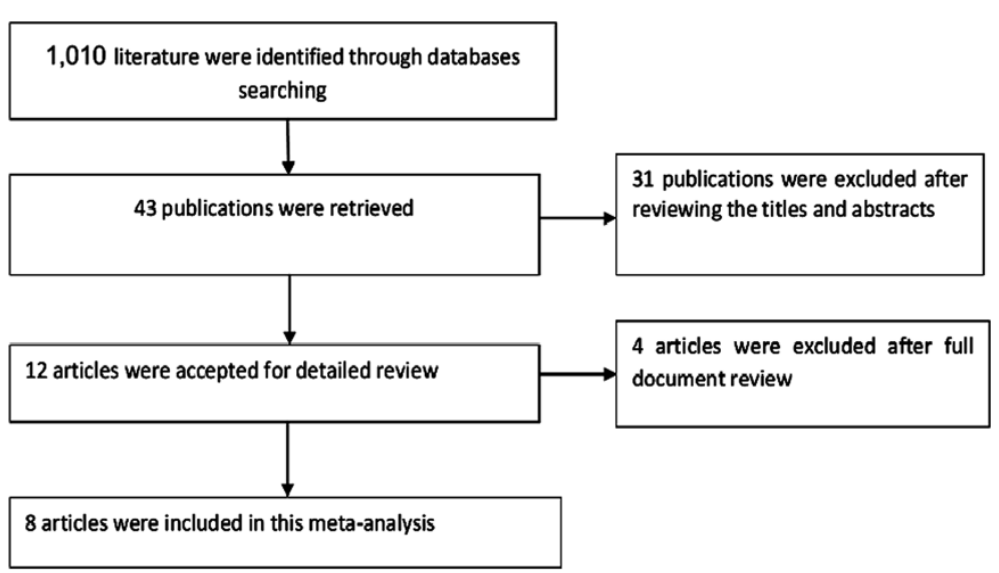

Figure 1 Flow diagram showing studies selection. 
Table 1 Summary of the randomized controlled trials (RCTs) included in this meta-analysis

\begin{tabular}{|c|c|c|c|c|c|c|c|c|}
\hline Author & Year & $\begin{array}{l}\text { Phase of } \\
\text { the trial }\end{array}$ & $\begin{array}{l}\text { Duration } \\
\text { of therapy }\end{array}$ & Intervention arm-1 & Intervention arm-2 & Intervention arm-3 & Intervention arm-4 & Control arm \\
\hline Kremer JM et al. study 1 [18] & 2012 & Phase Ilb & 24-weeks & $\begin{array}{l}\text { Tofacitinib 3-mg BID + } \\
\text { Methotrexate }(\mathrm{N}=68)\end{array}$ & $\begin{array}{l}\text { Tofacitinib 5-mg BID + } \\
\text { Methotrexate }(\mathrm{N}=71)\end{array}$ & $\begin{array}{l}\text { Tofacitinib 10-mg BID + } \\
\text { Methotrexate }(\mathrm{N}=74)\end{array}$ & $\begin{array}{l}\text { Tofacitinib 15-mg BID + } \\
\text { Methotrexate }(\mathrm{N}=75)\end{array}$ & $\begin{array}{l}\text { Placebo + Methotrexate } \\
(\mathrm{N}=69)\end{array}$ \\
\hline Tanaka Y et al. [19] & 2011 & Phase II & 12-weeks & $\begin{array}{l}\text { Tofacitinib 3-mg BID + } \\
\text { Methotrexate (28) }\end{array}$ & $\begin{array}{l}\text { Tofacitinib 5-mg BID + } \\
\text { Methotrexate }(\mathrm{N}=28)\end{array}$ & $\begin{array}{l}\text { Tofacitinib 10-mg BID + } \\
\text { Methotrexate }(\mathrm{N}=28)\end{array}$ & .. & $\begin{array}{l}\text { Placebo + Methotrexate } \\
(\mathrm{N}=28)\end{array}$ \\
\hline Fleischmann R et al. study 1 [16] & 2012 & Phase Ilb & 24-weeks & $\begin{array}{l}\text { Tofacitinib 3-mg BID } \\
(N=51)\end{array}$ & $\begin{array}{l}\text { Tofacitinib 5-mg BID } \\
(N=49)\end{array}$ & $\begin{array}{l}\text { Tofacitinib 10-mg BID } \\
(\mathrm{N}=61)\end{array}$ & $\begin{array}{l}\text { Tofacitinib 15-mg BID } \\
(N=57)\end{array}$ & Placebo $(N=59)$ \\
\hline Fleischmann R et al. study 2 [11] & 2012 & Phase III & 6-months & .. & $\begin{array}{l}\text { Tofacitinib 5-mg BID } \\
(\mathrm{N}=243)\end{array}$ & $\begin{array}{l}\text { Tofacitinib 10-mg BID } \\
(\mathrm{N}=245)\end{array}$ & .. & Placebo $(\mathrm{N}=122)$ \\
\hline Kremer JM et al. study 2 [17] & 2009 & Phase lla & 12-weeks & & $\begin{array}{l}\text { Tofacitinib 5-mg BID } \\
(\mathrm{N}=61)\end{array}$ & .. & $\begin{array}{l}\text { Tofacitinib 15-mg BID } \\
(N=69)\end{array}$ & Placebo $(\mathrm{N}=65)$ \\
\hline Burmester GR et al. [10] & 2013 & Phase III & 6-months & $\ldots$ & $\begin{array}{l}\text { Tofacitinib 5-mg BID + } \\
\text { Methotrexate }(\mathrm{N}=133)\end{array}$ & $\begin{array}{l}\text { Tofacitinib 10-mg BID + } \\
\text { Methotrexate }(\mathrm{N}=134)\end{array}$ & & $\begin{array}{l}\text { Placebo + Methotrexate } \\
(\mathrm{N}=132)\end{array}$ \\
\hline van der Heijde D et al. [12] & 2013 & Phase III & 24-month & .. & $\begin{array}{l}\text { Tofacitinib 5-mg BID + } \\
\text { Methotrexate }(\mathrm{N}=321)\end{array}$ & $\begin{array}{l}\text { Tofacitinib 10-mg BID + } \\
\text { Methotrexate }(\mathrm{N}=316)\end{array}$ &. & $\begin{array}{l}\text { Placebo + Methotrexate } \\
(\mathrm{N}=160)\end{array}$ \\
\hline van Vollenhoven RF et al. [13] & 2012 & Phase III & 12-month & .. & $\begin{array}{l}\text { Tofacitinib 5-mg BID + } \\
\text { Methotrexate }(\mathrm{N}=204)\end{array}$ & $\begin{array}{l}\text { Tofacitinib 10-mg BID + } \\
\text { Methotrexate }(\mathrm{N}=201)\end{array}$ & .. & $\begin{array}{l}\text { Placebo + Methotrexate } \\
(\mathrm{N}=108)\end{array}$ \\
\hline
\end{tabular}




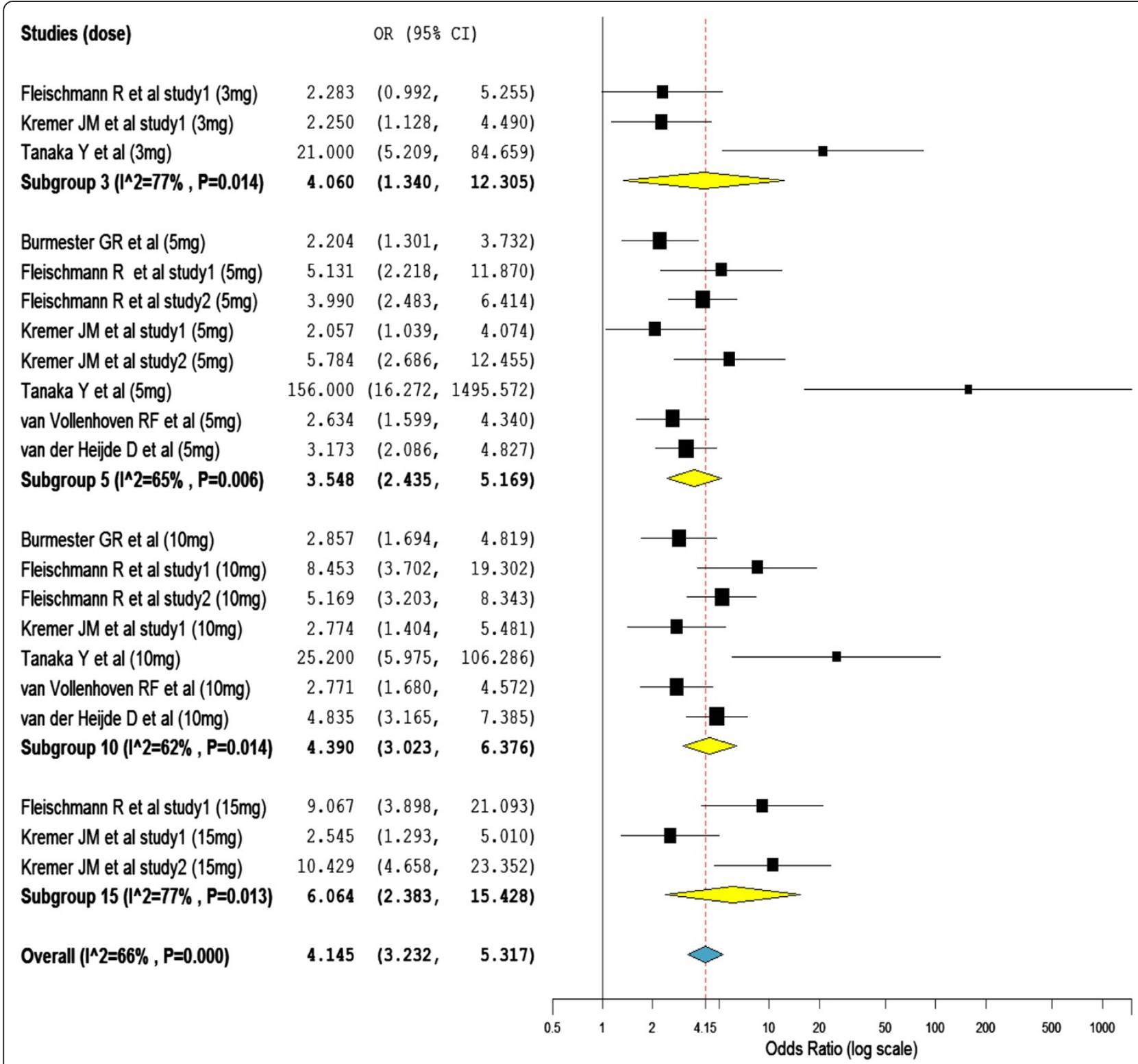

Figure 2 Mantel-Haenszel odds ratio of at least a 20\% improvement in the American College of Rheumatology scale (ACR 20).

included studies the ACR 20 response rates for patients receiving all tofacitinib dosages $\geq 3$-mg BID was significantly greater than those who received placebo. Nevertheless, the subgroup odds ratios in the subgroups of tofacitinib 10-mg (subgroup OR $=4.3$; $95 \% \mathrm{CI}, 3.023$ to 6.376) and $15-\mathrm{mg}$ (subgroup $\mathrm{OR}=6.06 ; 95 \% \mathrm{CI}, 2.383$ to 15.428) was higher than tofacitinib 3-mg (subgroup $\mathrm{OR}=4.06 ; 95 \% \mathrm{CI}, 1.340$ to 12.305 ) and 5 -mg (subgroup $\mathrm{OR}=3.55$; $95 \% \mathrm{CI}, 2.435$ to 5.169 ) treated groups.

Heterogeneity testing has unveiled the presence of significant inconsistency (heterogeneity) among the included studies $\left(\mathrm{I}^{2}=66 \%\right)$. The subgroup analysis showed, the variations in the types of therapy (tofacitinib monotherapy vs tofacitinib combined with methotrexate) among the included studies was not enough to explain the sources of heterogeneity. The treatment outcomes with tofacitinib monotherapy were not significantly different from the combination of tofacitinib with background methotrexate. Similarly, linear meta-regressions based on the duration of therapy and doses of tofacitinib did not show a significant variation in the therapeutic outcome across studies. However, sensitivity analysis has confirmed the robustness of the overall value; when any of the study was excluded from the analysis the overall odds ratio swings within the range of 3.63 to 4.79 .

The meta-analysis of change in HAQ-DI scores from baseline presents further evidence that supports the efficacy of tofacitinib in the treatment of rheumatoid 
arthritis (Figure 3). This is to mean, a statistically significant improvement in HAQ-DI scores were seen in patients who were on tofacitinib than placebo treated patients (overall SMD $=-0.62,95 \% \mathrm{CI}=-0.735$ to -0.506 ). Furthermore, in all the included studies, patients who were treated with a greater than or equal to 5-mg of tofacitinib BID have shown a statistically significant reduction in HAQ- DI scores. Heterogeneity testing showed no significant variation among the included studies.

\section{Safety and tolerability}

As shown in Figure 4, the proportion of infections was higher in the tofacitinib treated groups than in the placebo groups (overall $\mathrm{SMD}=1.96,95 \% \mathrm{CI}=1.428$ to 2.676 ). Nonetheless, unlike in the subgroups of tofacitinib 10-mg (subgroup $\mathrm{SMD}=3.08,95 \% \mathrm{CI}=1.694$ to 5.570 ) and $15-\mathrm{mg}$ (subgroup $\mathrm{SMD}=1.97,95 \% \mathrm{CI}=1.088$ to 3.558 ), the proportion of infections in the subgroups of tofacitinib 3-mg (subgroup SMD $=1.64,95 \% \mathrm{CI}=0.858$ to 3.142 ) and 5 -mg (subgroup $\mathrm{SMD}=1.52,95 \% \mathrm{CI}=0.644$ to 3.594 ) were not significantly different from placebo.

Whilst, with a significant heterogeneity $\left(\mathrm{I}^{2}=52 \%\right)$, tofacitinib treatment was significantly associated with reduction in neutrophil counts (overall SMD $=-0.34,95 \%$ $\mathrm{CI}=-0.450$ to -0.223 ) (Figure 5 ). The subgroups SMDs were not significant in the subgroups of tofacitinib 3-mg and 15-mg; but the numbers of studies in the subgroups were very small (only 2 studies in both subgroups).

On the contrary, the mean hemoglobin level has increased significantly from baselines in tofacitinib treated groups (overall $\mathrm{SMD}=0.11,95 \% \mathrm{CI}=0.130$ to 0.210 ) (see Additional file 1). Even though the overall SMD was statistically significant, the mean hemoglobin level was increased significantly only in the subgroup of tofacitinib 5-mg (subgroup SMD $=0.22,95 \% \mathrm{CI}=0.039$ to 0.392 ). Similarly, mean serum creatinine (overall $\mathrm{SMD}=0.24$,

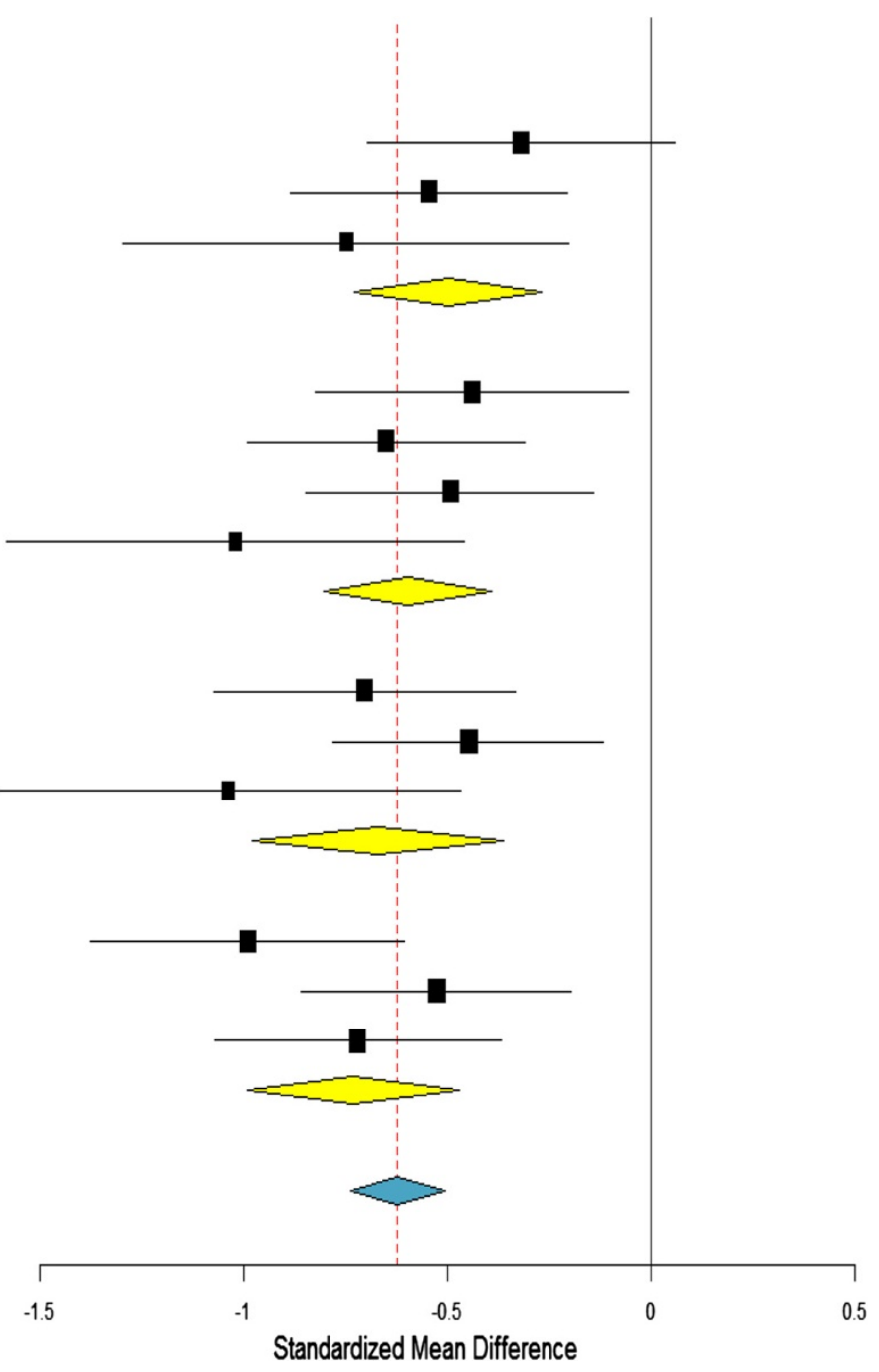

Standardized Mean Difference

Figure 3 Standardize mean difference of change in the Health Assessment Questionnaire-Disability Index (HAQ DI) Scores. 


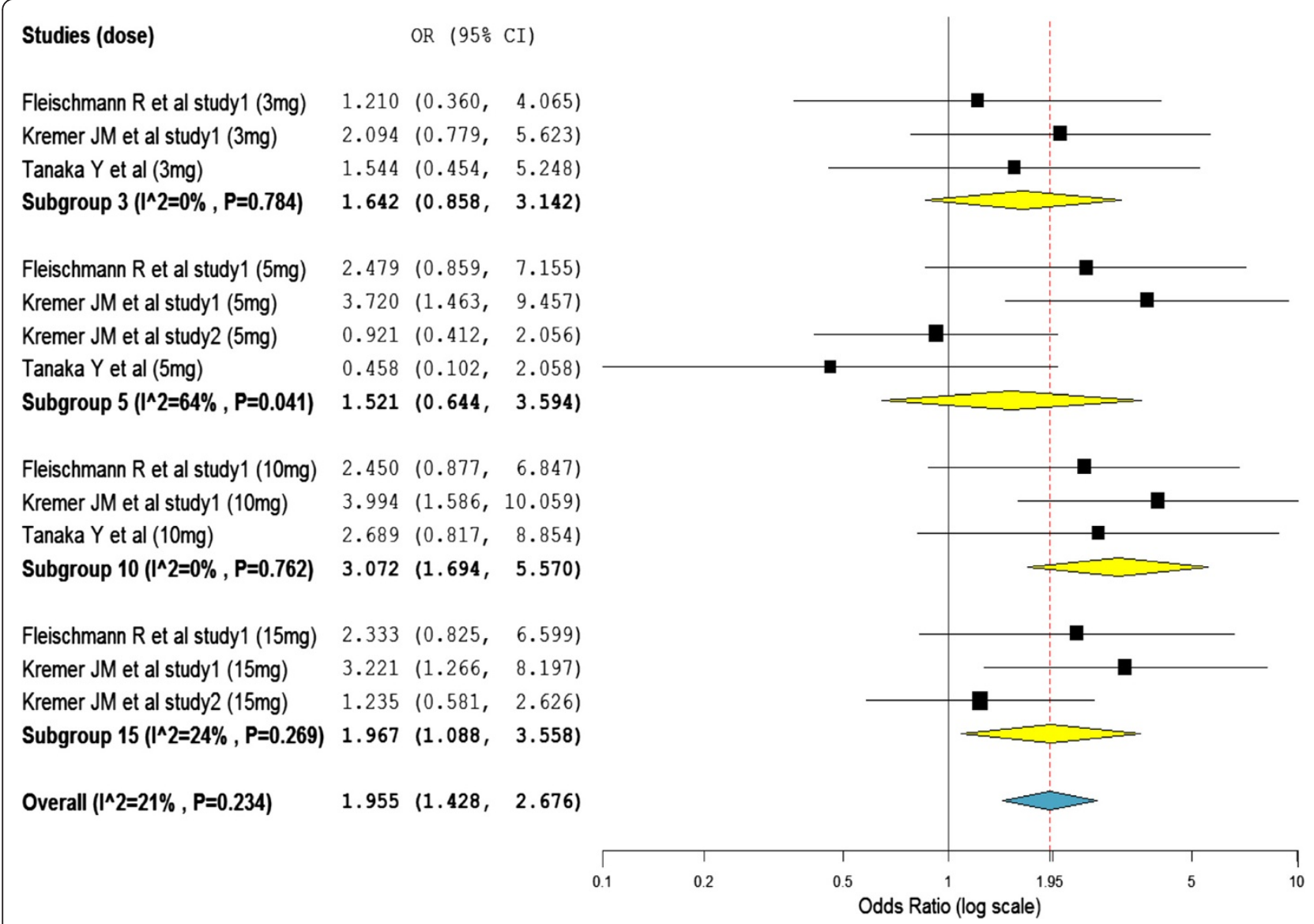

Figure 4 Mantel-Haenszel odds ratio of patients reporting treatment emergent infections.

95\% CI $=0.112$ to 0.372 ) (see Additional file 2), HDLcholesterol (overall $\mathrm{SMD}=1.01,95 \% \mathrm{CI}=0.332$ to 1.682 ) (see Additional file 3), and LDL-cholesterol (overall SMD = $0.95,95 \% \mathrm{CI}=0.337$ to 1.555 ) (see Additional file 4) levels have increased significantly in tofacitinib treated groups. The significant increments in mean serum creatinine, HDL- cholesterol, and LDL-cholesterol levels were consistent in tofacitinib 5-mg and 10-mg treated groups.

Furthermore, a significant number of patients with ALT $>1$ X ULN (overall OR $=1.7 ; 95 \%$ CI, 1.29 to 2.46) (see Additional file 5) and AST $>1$ X ULN (overall OR = 2.19; $95 \% \mathrm{CI}, 1.50$ to 3.19) (see Additional file 6) were reported among tofacitinib treated groups. Yet, unlike in the subgroups of 10-mg and 15-mg the number of patients who were treated with tofacitinib and had elevated levels of both liver enzymes (ALT and AST) in the subgroup of 3-mg were not significantly different from placebo treated. In the 5-mg subgroup, a significant number of patients have had an increased level of AST level but not ALT level.

But, as presented in Figure 6, the comparison based on the number of patients who discontinued treatment due to adverse events did not show a significant difference (overall $\mathrm{SMD}=1.27,95 \% \mathrm{CI}=0.949$ to 1.700 ). This is to mean, the number of patients who discontinued medication because of treatment-emergent adverse events in the tofacitinib treated groups was not significantly different from placebo treated groups. As shown on the forest plot, patients who were treated with tofacitinib 15-mg BID was more likely to discontinue medication than those patients who were on other smaller doses of tofacitinib.

\section{Discussion}

This meta-analysis has demonstrated the efficacy of tofacitinib in the treatment of active rheumatoid arthritis in patients with an inadequate response to at least one DMARDs. That is, although all the recruited patients with rheumatoid arthritis had an inadequate response or intolerance to at least one DMARDs and had active disease on the basis of the ACR 1987 revised criteria, a significant improvement in physical functions and a significant reduction in the signs and symptoms of the disease were seen in tofacitinib treated patients.

ACR20 response rates and change in HAQ-DI were significant in all tofacitinib treatment groups $\geq 3-\mathrm{mg}(3,5,10$ or 15-mg) BID than placebo groups. However, there was a 


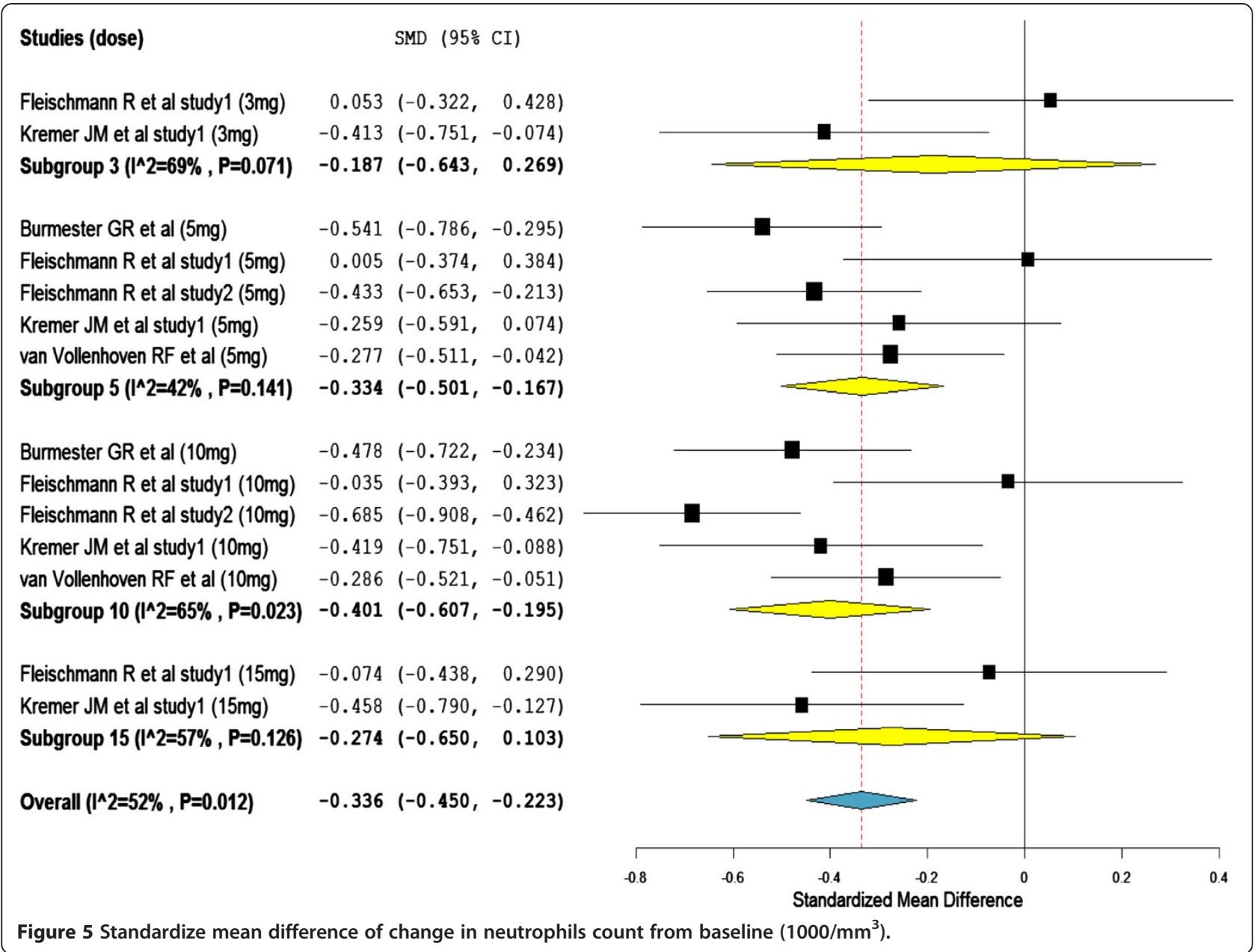

significant heterogeneity among the included studies. But sensitivity analysis has demonstrated the stability of the pooled values. Accordingly the conclusiveness of the results (ACR20 response rates and change in HAQ-DI) of this meta-analysis did not seem compromised. When there was a significant heterogeneity among the included studies whilst the number of included studies was small, the robustness of the pooled values was best assessed with sensitivity analysis [20].

Tofacitinib monotherapy was as effective as tofacitinib with background methotrexate. However, this finding (tofacitinib monotherapy vs tofacitinib in combination with methotrexate) must be interpreted with great caution. Most of the studies which evaluated the efficacy of tofacitinib in combination with methotrexate recruited patients with a criterion of "inadequate response to at least one nonbiologic or biologic disease-modifying drug" $[13,18,19]$. In contrary, studies which compared the efficacy of tofacitinib monotherapy against placebo did not clearly state this criterion $[11,16,17]$. As a result, the disease state in the recruited patients may be at the earlier stage and could respond better to treatment. Additionally, a previous systematic review and meta-analysis of combination and monotherapy treatments in DMARD-experienced patients with rheumatoid arthritis has shown the superiority of combination therapy to monotherapy [21].

Even though the primary studies reported the manageable safety profile of tofacitinib over the treatment periods $[10,16,18,19]$, this meta-analysis has established the significant association of tofacitinib with infections, decreased level of neutrophil and increased levels of hemoglobin, creatinine and liver enzymes (ALT and AST). Similarly, an increase in HDL and LDL cholesterol were observed in patients with rheumatoid arthritis who were treated with tofacitinib.

Though subgroup analysis did not show a significant difference when tofacitinib was used as monotherapy and in combination with background methotrexate, the significant association of tofacitinib with infection and laboratory abnormalities could also be partly attributed to methotrexate. Previous studies have confirmed the association of methotrexate with infections, hematological problems and hepatotoxicity [22-25]. Still, all the included studies in the meta-analysis have allowed stable 


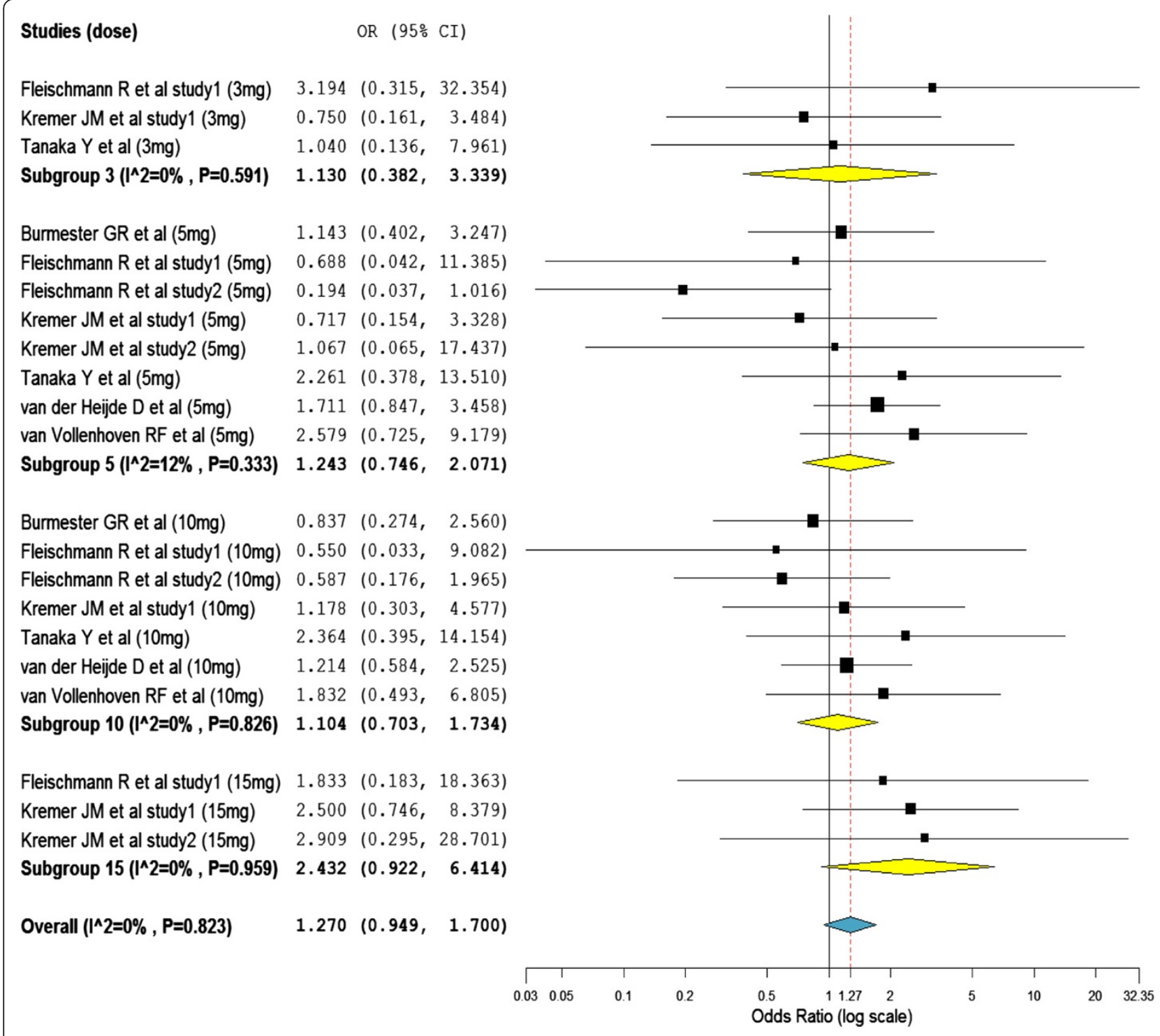

Figure 6 Mantel-Haenszel odds ratio of patients who discontinued the treatment due to treatment-emergent adverse events.

doses of low-dose corticosteroids as a background regimen; thus costicosterioids could also have contributed for the tofacitinib associated infection and immune suppressions [26,27]. While, as verified by a randomized double- blind study, the elevated level of LDL cholesterol in tofacitinib treated patients with rheumatoid arthritis seem to be managed by adding statins to the regimens [28].

Nevertheless, this meta-analysis has also shown that the number of tofacitinib treated patients who discontinued medication due to adverse events were not different from placebo treated groups. Moreover, the included studies in this meta-analysis were not primarily designed to assess tofacitinib related adverse events. As a result, the significant association of tofacitinib with infections and laboratory abnormalities might not be conclusive. A meta-analysis including studies which were not designed to assess adverse events and have had small sample sizes may not have an adequate power to test rare adverse events [29].

As limitations, first, this meta-analysis has noted a significant heterogeneity among the included studies. The possible explanation for the significant heterogeneity among the included studies could be: 1 ) the differences in the baseline demographic and clinical characteristics of the patients recruited in the studies. 2) The variation in the duration of therapy and the drug regimens (tofacitinib monotherapy vs tofacitinib with background methotrexate) across studies. Nonetheless, these assumptions were not supported by either the subgroup analysis or meta-regression; that is to say, the treatment outcome did not seem to be affected by the duration of therapy and by the use of 
tofacitinib as monotherapy or in combination with methotrexate. Second, since most of the included studies did not report values for ACR50, and ACR70 responses, meta- analyses were not conducted with these outcome indicators. Third, all the primary studies included in this meta-analysis were sponsored by a pharmaceutical company. Studies sponsored by pharmaceutical companies were more likely to have outcomes favoring the sponsor interests [30,31]. Fourth, this meta-analysis did not to incorporate studies written in other languages.

\section{Conclusion}

In conclusion, tofacitinib monotherapy or in combination with background methotrexate was effective in the treatment of active rheumatoid arthritis in patients with an inadequate response or intolerance to at least one of the nonbiologic or biologic DMARDs. Additionally, the number of patients who discontinued medication in the tofacitinib treatment groups was not different from placebo groups. However, treatment with tofacitinib was associated with infections and laboratory abnormalities. Accordingly, further studies that are primarily designed to assess tofacitinib related adverse events and have a longer duration of therapy with a large number of patients are warranted.

\section{Additional files}

\section{Additional file 1: Standardize mean difference of the change in} hemoglobin from baseline $(\mathrm{mg} / \mathrm{dl})$.

Additional file 2: Standardize mean difference of change in serum creatinine level from baseline $(\mathrm{mg} / \mathrm{dl})$.

Additional file 3: Standardize mean difference of change in HDL cholesterol level from baseline ( $\mathrm{mg} / \mathrm{dl})$.

Additional file 4: Standardize mean difference of the change in LDL cholesterol level from baseline ( $\mathrm{mg} / \mathrm{dl})$.

Additional file 5: Mantel-Haenszel odds ratio of ALT $>1 \times$ ULN range.

Additional file 6: Mantel-Haenszel odds ratio of AST > $1 \times$ ULN range.

\section{Abbreviations \\ DMARDs: Disease-modifying antirheumatic drugs; HINARI: Health internetwork access to research initiative; ACR 20: A 20\% improvement in the American College of Rheumatology scale; HAQ DI: Health assessment questionnaire-disability index; TNF: Tumor necrosis factor; CRP: C-reactive protein; ALT: Alanine aminotransferase; AST: Aspartate aminotransferase; LDL: Low-density lipoprotein; HDL: High-density lipoprotein; ESR: Erythrocyte sedimentation rate; ULN: Upper limit of the normal range; BID: Twice daily; FDA: Food and drug administration; SMD: Standardized mean differences; OR: Odds ratios; Cl: Confidence intervals; SE: Standard errors; SD: Standard deviations.}

\section{Competing interests}

The author declares that he has no competing interests.

\section{Acknowledgment}

The author would like to thank WHO and publishers for setting up HINARI.

Otherwise, this analysis has not got any financial or technical support.
Received: 16 July 2013 Accepted: 25 November 2013

Published: 26 November 2013

\section{References}

1. Smolen JS, Aletaha D, Bijlsma JWJ, Breedveld FC, Boumpas D, Burmester G, Combe B, Cutolo M, de Wit M, Dougados M, Emery P, Gibofsky A, Gomez-Reino JJ, Haraoui B, Kalden J, Keystone EC, Kvien TK, McInnes I, Martin-Mola E, Montecucco C, Schoels M, van der Heijde D: Treating rheumatoid arthritis to target: recommendations of an international task force. Ann Rheum Dis 2010, 69:631-637.

2. Saag KG, Teng GG, Patkar NM, Anuntiyo J, Finney C, Curtis JR, Paulus HE, Mudano AM, Pisu M, Elkins-Melton M, Outman R, Allison JJ, Almazor MS, Bridges SL, Chatham WW, Hochberg M, Maclean C, Mikuls T, Moreland LW O'Dell J, Turkiewicz AM, Furst DE: American College of Rheumatology 2008 recommendations for the use of nonbiologic and biologic disease-modifying antirheumatic drugs in rheumatoid arthritis. Arthritis Rheum 2008, 59:762-784

3. Mikuls TR, O'Dell J: The changing face of rheumatoid arthritis therapy: results of serial surveys. Arthritis Rheum 2000, 43(2):464-467.

4. O'Dell JR: Therapeutic strategies for rheumatoid arthritis. N Engl J Med 2004, 350:2591-2602.

5. Yazici Y: Treatment of rheumatoid arthritis: we are getting there. Lancet 2009, 374:178-180.

6. Bathon JM, Martin RW, Fleischmann RM, Tesser JR, Schiff MH, Keystone EC, Genovese MC, Wasko MC, Moreland LW, Weaver AL, Markenson J, Finck BK: A comparison of etanercept and methotrexate in patients with early rheumatoid arthritis. N Engl J Med 2000, 343(22):1586-1593.

7. Klareskog L, van der Heijde D, de Jager JP, Gough A, Kalden J, Malaise M, Mola EM, Pavelka K, Sany J, Settas L, Wajdula J, Pedersen R, Fatenejad S, Sanda M: Therapeutic effect of the combination of etanercept and methotrexate compared with each treatment alone in patients with rheumatoid arthritis: double-blind randomised controlled trial. The Lancet 2004, 363(9410):675-681.

8. LaBranche TP, Jesson MI, Radi ZA, Storer CE, Guzova JA, Bonar SL, Thompson JM, Happa FA, Stewart ZS, Zhan Y, Bollinger CS, Bansal PN, Wellen JW, Wilkie DP, Bailey SA, Symanowicz PT, Hegen M, Head RD, Kishore N, Mbalaviele G, Meyer DM: JAK inhibition with tofacitinib suppresses arthritic joint structural damage through decreased RANKL production. Arthritis Rheum 2012, 64(11):3531-3542.

9. Maeshima K, Yamaoka K, Kubo S, Nakano K, Iwata S, Saito K, Ohishi M, Miyahara H, Tanaka S, Ishii K, Yoshimatsu H, Tanaka Y: The JAK inhibitor tofacitinib regulates synovitis through inhibition of interferon and interleukin 17 production by human CD4+ T cells. Arthritis Rheum 2012, 64(6):1790-1798.

10. Burmester GR, Blanco R, Charles-Schoeman C, Wollenhaupt J, Zerbini C, Benda B, Gruben D, Wallenstein G, Krishnaswami S, Zwillich SH, Koncz T, Sama K, Bradley J, Mebus C: Tofacitinib (CP-690,550) in combination with methotrexate in patients with active rheumatoid arthritis with an inadequate response to tumour necrosis factor inhibitors: a randomised phase 3 trial. Lancet 2013, 381:451-460

11. Fleischmann R, Kremer J, Cush J, Schulze-Koops H, Connell CA, Bradley JD, Gruben D, Wallenstein GV, Zwillich SH, Kanik KS: Placebo-controlled trial of tofacitinib monotherapy in rheumatoid arthritis. N Engl J Med 2012, 367(6):495-507.

12. van der Heijde D, Tanaka Y, Fleischmann R, Keystone E, Kremer J, Zerbini C Cardiel MH, Cohen S, Nash P, Song Y, Tegzova D, Wyman BT, Gruben D, Benda B, Wallenstein G, Krishnaswami S, Zwillich SH, Bradley JD, Connell CA: Tofacitinib (CP690,550) in patients with rheumatoid arthritis receiving methotrexate: Twelvemonth data from a twenty four month phase III randomized radiographic study. Arthritis Rheum 2013, 65(3):559-570.

13. van Vollenhoven RF, Fleischmann R, Cohen S, Lee EB, Meijide JAG, Wagner S, Forejtova S, Zwillich SH, Gruben D, Koncz T, Wallenstein GV, Krishnaswami S, Bradley JD, Wilkinson B: Tofacitinib or adalimumab versus placebo in rheumatoid arthritis. N Engl J Med 2012, 367(6):508-519.

14. Arnett FC, Edworthy SM, Bloch DA, McShane DJ, Fries JF, Cooper NS, Jealey LA, Kaplan SR, Liang MH, Neustadt DH, Pinals RS, Schaller JG, Sharp JT, Wilder RL, Hunder GG: The American Rheumatism Association 1987 revised criteria for the classification of rheumatoid arthritis. Arthritis Rheum 1988, 31(3):315-324.

15. Sterne JAC, Sutton AJ, loannidis JPA, Terrin N, Jones DR, Lau J, Carpenter J, Rücker G, Harbord RM, Schmid CH, Tetzlaff J, Deeks JJ, Peters J, Macaskill P, 
Schwarzer G, Duva S, Altman DG, Moher D, Higgins JPT: Recommendations for examining and interpreting funnel plot asymmetry in meta-analyses of randomised controlled trials. BMJ 2011, 342(d4002). doi:10.1136/bmj.d4002.

16. Fleischmann R, Cutolo M, Genovese MC, Lee EB, Kanik KS, Sadis S, Connell CA, Gruben D, Krishnaswami S, Wallenstein G, Wilkinson BE, Zwillich SH: Phase llb doseranging study of the oral JAK inhibitor tofacitinib $(\mathrm{CP} 690,550)$ or adalimumab monotherapy versus placebo in patients with active rheumatoid arthritis with an inadequate response to diseasemodifying antirheumatic drugs. Arthritis Rheum 2012, 64(3):617-629.

17. Kremer JM, Bloom BJ, Breedveld FC, Coombs JH, Fletcher MP, Gruben D, Krishnaswami S, Burgos-Vargas R, Wilkinson B, Zerbini CAF, Zwillich SH: The safety and efficacy of a JAK inhibitor in patients with active rheumatoid arthritis: Results of a double-blind, placebo-controlled phase lla trial of three dosage levels of CP-690,550 versus placebo. Arthritis Rheum 2009, 60(7):1895-1905.

18. Kremer JM, Cohen S, Wilkinson BE, Connell CA, French JL, Gomez-Reino J, Gruben D, Kanik KS, Krishnaswami S, Pascual-Ramos V, Wallenstein G, Zwillich SH: A phase lllb doseranging study of the oral JAK inhibitor tofacitinib $(\mathrm{CP} 690,550)$ versus placebo in combination with background methotrexate in patients with active rheumatoid arthritis and an inadequate response to methotrexate alone. Arthritis Rheum 2012. 64(4):970-981.

19. Tanaka Y, Suzuki M, Nakamura H, Toyoizumi S, Zwillich SH: Phase II study of tofacitinib $(C P 690,550)$ combined with methotrexate in patients with rheumatoid arthritis and an inadequate response to methotrexate. Arthrit Care Res 2011, 63(8):1150-1158.

20. Fanelli D: How many scientists fabricate and falsify research? a systematic review and meta-analysis of survey data. PLoS One 2009, 4(5):e5738. doi:10.1371/journal.pone.0005738.

21. Orme ME, MacGilchrist KS, Mitchell S, Spurden D, Bird A: Systematic review and network meta-analysis of combination and monotherapy treatments in disease-modifying antirheumatic drug-experienced patients with rheumatoid arthritis: analysis of American College of Rheumatology criteria scores 20, 50, and 70. BTT 2012, 6:429-464.

22. Salliot $C$, van der Heijde D: Long-term safety of methotrexate monotherapy in patients with rheumatoid arthritis: a systematic literature research. Ann Rheum Dis 2009, 68(7):1100-1104.

23. McLean-Tooke A, Aldridge C, Waugh S, Spickett GP, Kay L: Methotrexate, rheumatoid arthritis and infection risk-what is the evidence? Rheumatology 2009, 48:867-871.

24. Greenberg SB: Infections in the immunocompromised rheumatologic patient. Crit Care Clin 2002, 18:931-956.

25. Gilani STA, Khan DA, Khan FA, Ahmed M: Adverse effects of low dose methotrexate in rheumatoid arthritis patients. JCPSP 2012, 22(2):101-104

26. Doran MF, Crowson CS, Pond GR, O'Fallon WM, Gabriel SE: Predictors of infection in rheumatoid arthritis. Arthritis Rheum 2002, 46(9):2294-2300.

27. Ruyssen-Witrand A, Fautrel B, Saraux A, Le-LoÃet X, Pham T: Infections induced by low-dose corticosteroids in rheumatoid arthritis: a systematic literature review. Joint Bone Spine 2010, 77:246-251.

28. McInnes IB, Kim H, Lee S, Mandel D, Song Y, Connell CA, Luo Z, Brosnan MJ, Zuckerman A, Zwillich SH, Bradley JD: Open-label tofacitinib and double-blind atorvastatin in rheumatoid arthritis patients: a randomised study. Ann Rheum Dis 2013, 0:1-8.

29. Walker $E$, Hernandez AV, kattan $m$ W: Meta-analysis: its strengths an meta-analysis: its strengths and limitations. Clev Clin J Med 2008, 75(6):431-439

30. Lexchin J, Bero LA, Djulbegovic B, Clark O: Pharmaceutical industry sponsorship and research outcome and quality: systematic review. BMJ 2003, 326:1167.

31. Sismondo S: Pharmaceutical company funding and its consequences: a qualitative systematic review. Contemp Clin Trials 2008, 25:109-113.

\section{doi:10.1186/1471-2474-14-332}

Cite this article as: Berhan: Efficacy, safety and tolerability of tofacitinib in patients with an inadequate response to disease modifying anti-rheumatic drugs: a meta-analysis of randomized double-blind controlled studies. BMC Musculoskeletal Disorders 2013 14:332.

\section{Submit your next manuscript to BioMed Central and take full advantage of:}

- Convenient online submission

- Thorough peer review

- No space constraints or color figure charges

- Immediate publication on acceptance

- Inclusion in PubMed, CAS, Scopus and Google Scholar

- Research which is freely available for redistribution

Submit your manuscript at www.biomedcentral.com/submit
() Biomed Central 